Article

\title{
Hierarchical mesoporous ZSM-5 zeolite with increased external surface acid sites and high catalytic performance in $o$-xylene isomerization
}

\author{
ZHOU Jian ${ }^{\mathrm{a}, \mathrm{b}}$, LIU Zhicheng ${ }^{\mathrm{a}, *}$, LI Liyuan a, WANG Yangdong a, GAO Huanxin ${ }^{\mathrm{a}}$, YANG Weimin ${ }^{\mathrm{a}}$, \\ XIE Zaiku ${ }^{a, \#,}$ TANG Yi ${ }^{b}$ \\ a Shanghai Research Institute of Petrochemical Technology, SINOPEC, Shanghai 201208, China \\ ${ }^{\mathrm{b}}$ Department of Chemistry, Fudan University, Shanghai 200433, China
}

\section{A R T I C L E I N F O}

Article history:

Received 24 February 2013

Accepted 10 April 2013

Published 20 July 2013

\section{Keywords:}

Hierarchical structure

ZSM-5 zeolite

Surface acid site

Catalysis

Xylene isomerization

\begin{abstract}
A B S T R A C T
Surface acid sites of hierarchical mesoporous ZSM- 5 zeolite synthesized by steam-assisted crystallization were characterized by $\mathrm{NH}_{3}$ temperature-programmed desorption and in-situ infrared spectroscopy. Compared with the conventional ZSM-5 zeolite, the hierarchical ZSM-5 zeolite had a lower concentration of surface acid sites. However, the hierarchical structure had more Lewis acid sites and, more importantly, much more external active sites as confirmed by 2,6-di-tert-butylpyridine infrared spectroscopy. Such hierarchical structure exposed more acid sites on the external surface, which subsequently lead to higher catalytic activity in reactions involving bulky molecules, such as $o$-xylene isomerization.
\end{abstract}

(C) 2013, Dalian Institute of Chemical Physics, Chinese Academy of Sciences. Published by Elsevier B.V. All rights reserved.

\section{Introduction}

Zeolites have found wide application in recent decades in the petrochemical, fine chemicals, and environmental fields because of their unique structure, high stability, and activity [1]. Recently, however, research has demonstrated that zeolite catalysts are mass transport limited by the inherent small size of their microporous networks [2]. Because of the difficulty in manufacture of crystalline zeolites with larger pores [1,2] amorphous mesoporous materials, usually with a pore size larger than $2 \mathrm{~nm}$, have drawn significant attention in recent years. However, their application in severe atmospheres is lim- ited by their amorphous structure and lower hydrothermal stability [2-5].

Therefore, constructing macro/mesopores in zeolites to achieve a so-called hierarchical porous structure has been of great interest to researchers in recent decades [4-6]. Many procedures including zeolite nanoparticle assembly [7], hard-templating [8], supramolecular templating [9-11], post-steaming treatment [12,13], and desilication [14] are available for the synthesis of hierarchical zeolites. More importantly, such hierarchical porous structures demonstrate improved diffusion properties and, consequently, higher catalytic activity than conventional zeolites in reactions involving

\footnotetext{
*Corresponding author. Tel: +86-21-68462197; Fax: +86-21-68462283; E-mail: liuzc.sshy@sinopec.com

\# Corresponding author. Tel: +86-21-68462197; Fax: +86-21-68462283; E-mail: xzk@sinopec.com

This work was supported by the National Basic Research Program of China (973 Program, 2009CB623506), the China Postdoctoral Science Foundation Project (2012M510101), the Opening Project of State Key Laboratory of High Performance Ceramics and Superfine Microstructure (SKL201208SIC), and the Shanghai Postdoctoral Scientific Program (12R21422000).

DOI: 10.1016/S1872-2067(12)60602-0 | http://www.sciencedirect.com/science/journal/18722067 | Chin. J. Catal., Vol. 34, No. 7, July 2013
} 
bulky molecules, such as catalytic cracking [13], alkylation of benzene [15], and epoxidation of olefins [16]. In most cases, however, the construction of mesopores into zeolites destroys the zeolite crystallinity, and the quantity and distribution of acid sites are impacted. Therefore, much attention should be given to the research of surface properties of the hierarchical structure. To date, although the improved catalytic properties testify to the improvement in transport diffusion of hierarchical zeolites in many reports [5,6,15-17], few reports focus on the investigation of the properties of surface acid sites.

Among the synthesis techniques for hierarchical zeolites, soft-templating methods, such as cationic [9] or silylated polymer [10] and amphiphilic organosilane [11], are of interest because of their high efficiency in creating mesoporosity. Unfortunately, much effort is still required for the design of such unusual templates, hence further application is limited. By employing conventional copolymers as soft templates, a direct synthesis route has been developed to synthesize hierarchical mesoporous ZSM-5 zeolites by post-steaming treatment $[12,13]$. The resultant hierarchical zeolite demonstrates a greatly enhanced catalytic activity for probe reactions involving bulky molecules because of the increased external surface and the greatly shortened diffusion length in the microporous networks [13]. However, no detailed investigations regarding the surface acid site properties have been conducted in these reports.

In this study, ammonia temperature-programmed desorption ( $\mathrm{NH}_{3}$-TPD) and pyridine and 2,6-di-tert-butylpyridine in-situ infrared spectroscopy (IR) were used to demonstrate the difference in surface acid sites of hierarchical ZSM-5 and conventional ZSM-5 zeolites. The catalytic properties of such zeolites in the isomerization of $o$-xylene were investigated.

\section{Experimental}

\subsection{Material synthesis}

The fabrication process of hierarchical ZSM-5 involves two key steps (reported elsewhere [12,13]): the sol-gel process of the zeolite precursors and copolymer template and, subsequently, steam-assisted crystallization (SAC) treatment. F127 (AR, BASF), aluminum isopropoxide $\left(\mathrm{C}_{9} \mathrm{H}_{21} \mathrm{AlO}_{3}, \mathrm{AR}\right.$, Sinopharm Chemical Reagent Co., Ltd. (SCRC), China), tetraethylorthosilicate (TEOS, AR, SCRC), and tetrapropylammonium hydroxide (TPAOH, 25\%, AR, Aldrich) were added dropwise and consecutively into distilled water under continuous stirring to obtain a solidified gel. The molar ratio of the precursors was $\mathrm{Al}_{2} \mathrm{O}_{3}: \mathrm{SiO}_{2}$ : F127:TPAOH: $\mathrm{H}_{2} \mathrm{O}=0.5: 100: 0.1: 8: 300$. The resultant wet gel was dried until there was no change in mass of the solid gel. The as-prepared gel was crystallized by the SAC method. The product was washed, filtered several times, dried overnight, and calcined to remove the remaining organic template. The obtained product, hierarchical mesoporous ZSM-5 zeolite, was termed Hier-ZSM-5. Conventional ZSM-5 was purchased from Shanghai Novel Chemical Co., Ltd., China.
Powder X-ray diffraction (XRD) experiments were conducted on a Bruker D8 Advance diffractometer equipped with $\mathrm{Cu} K \alpha$ source operated at $40 \mathrm{kV}$ and $40 \mathrm{~mA}$ with a scan rate of $2 \% \mathrm{~min}$.

Nitrogen adsorption-desorption isotherms were obtained on a Micromeritics ASAP 2010 apparatus. Before measurement, the samples were degassed at $250{ }^{\circ} \mathrm{C}$ for $3 \mathrm{~h}$ under vacuum. The specific surface area and pore volume were calculated by the BET and BJH methods, respectively, with a value of $p / p_{0}$ lower than 0.995 .

Field emission scanning electron microscopy (FE-SEM) analysis was performed on a JEOL JSM6700F electron microscope.

The $\mathrm{Al}$ content was determined by inductively coupled plasma atomic emission spectroscopy (ICP-AES) using a Varian Vista AX ICP-AES spectrometer.

$\mathrm{NH}_{3}$-TPD was performed on an apparatus built by Tianjin Golden Eagle Tech. Co., Ltd. Before the test, the sample was ion-exchanged by $\mathrm{NH}_{4} \mathrm{NO}_{3}$ aqueous solution and calcined at $400{ }^{\circ} \mathrm{C}$ for $6 \mathrm{~h}$. The ion-exchanged sample $(0.15 \mathrm{~g})$ was pre-treated at $600{ }^{\circ} \mathrm{C}$ for $1 \mathrm{~h}$ and then cooled to $50{ }^{\circ} \mathrm{C}$ under He flow. Pure $\mathrm{NH}_{3}$ was injected until adsorption saturation, followed by He flow for $30 \mathrm{~min}$. The temperature was raised from 100 to $550{ }^{\circ} \mathrm{C}$ at $10^{\circ} \mathrm{C} / \mathrm{min}$, and the amount of ammonia desorbed was detected by a TCD detector.

The pyridine (Py-IR) and 2,6-di-tert-butylpyridine infrared spectroscopy (DTBPy-IR) experiments were performed using a homemade vacuum adsorption system followed by IR testing. Tabletted samples were activated at $400{ }^{\circ} \mathrm{C}$ and then vacuumed to less than $0.1 \mathrm{~Pa}$ in the sealing system. Adsorption occurred at room temperature in a saturated atmosphere of Py or DTBPy for $30 \mathrm{~min}$, followed by degassing to less than $0.1 \mathrm{~Pa}$. In-situ IR spectra were recorded at a resolution of $2 \mathrm{~cm}^{-1}$ and $200{ }^{\circ} \mathrm{C}$. In all IR detecting tests, the sample mass and pressure used in the tabletting technique were kept the same.

\subsection{Isomerization of o-xylene}

The isomerization of $o$-xylene was performed in a microreactor. The catalyst $(0.1 \mathrm{~g})$ was pre-treated for $1 \mathrm{~h}$ at $500{ }^{\circ} \mathrm{C}$ under the $\mathrm{N}_{2}$ flow. After that, $o$-xylene was injected with a constant flow of $0.1 \mathrm{ml} / \mathrm{min}$ and $\mathrm{N}_{2}(50 \mathrm{ml} / \mathrm{min})$ was used as carrier gas. The testings of catalytic activity were performed at 300,400 , and $500{ }^{\circ} \mathrm{C}$, respectively, and the contents of products were analyzed using an on-line Agilent 5820 gas chromatograph equipped with an FID detector.

\section{Results and discussion}

\subsection{XRD and SEM results}

Figure 1 shows the XRD patterns of conventional ZSM-5 and hierarchical mesoporous ZSM-5 (Hier-ZSM-5) zeolites. The characteristic peaks of the MFI type zeolite can be identified, indicating crystallization of the ZSM-5-type zeolite. Furthermore, peak broadening $\left(2 \theta=23^{\circ}-25^{\circ}\right)$ and the weakened intensity can be associated with a decrease in crystallinity, which

\subsection{Characterization}




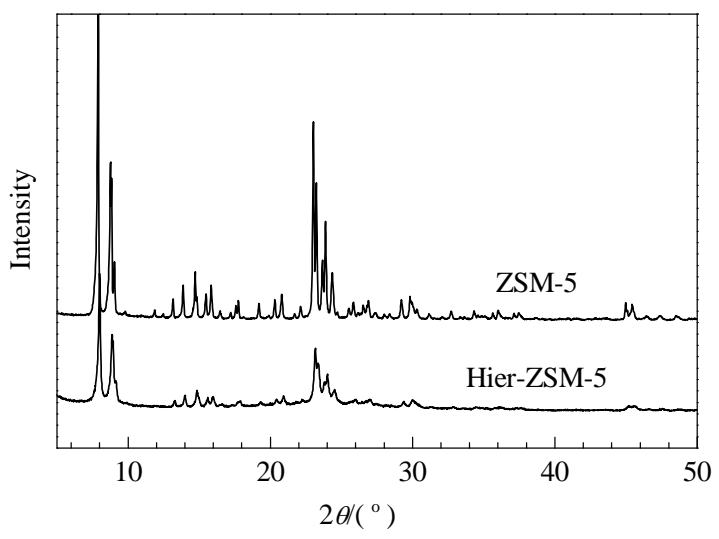

Fig. 1. XRD patterns of ZSM-5 and hierarchical ZSM-5 zeolites.

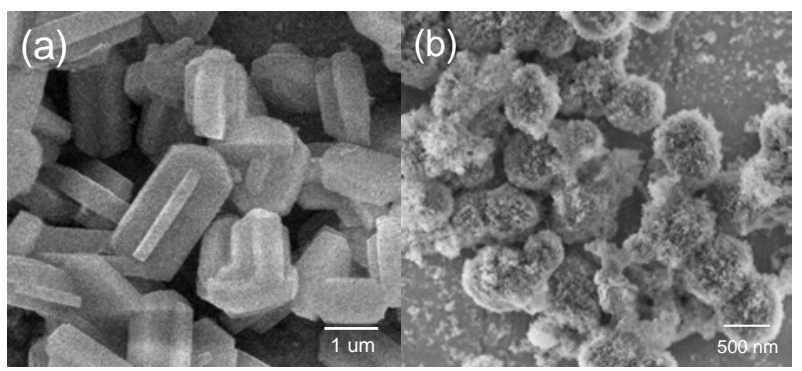

Fig. 2. SEM images of ZSM-5 (a) and hierarchical ZSM-5 (b) zeolites.

is usually found in the synthesis of nanomaterials and other reports on hierarchical mesoporous zeolites [9-14,17].

The SEM images of ZSM-5 and Hier-ZSM-5 (Fig. 2) highlight the difference in their particle morphology. For the ZSM-5, smooth intergrown flake-like particles larger than $1.5 \mu \mathrm{m}$ are visible. Comparatively, the representative Hier-ZSM-5 particles possess a spherical morphology with rough surface and relatively uniform diameter of approximately 500-700 nm. Such honeycomb-like morphology usually reveals a significant development in mesoporosity, which has also been found in other reports $[11,13,17]$.

\section{2. $\quad N_{2}$ adsorption-desorption results}

The $\mathrm{N}_{2}$ adsorption-desorption isotherm of Hier-ZSM-5 (Fig. 3 ) is a typical type-IV isotherm with capillary condensation at high relative pressure between 0.8 and 0.95 , suggesting a relatively large mesopore size. Comparatively, the negligible uptake in the isotherm of the conventional ZSM-5 zeolite at $p / p_{0}>0.1$ reveals the absence of its mesoporosity.

\section{3. $\mathrm{NH}_{3}-\mathrm{TPD}$ analysis}

The $\mathrm{NH}_{3}$-TPD profiles of the ZSM- 5 and Hier-ZSM- 5 zeolites are shown in Fig. 4. The two zeolites have similar-shaped curves at around $200{ }^{\circ} \mathrm{C}$. However, the curve intensity of $\mathrm{Hi}-$ er-ZSM-5 is lower than that of ZSM-5 and is much smaller at high temperature, indicating the weak strength of acid sites of Hier-ZSM-5 [18]. The area integral of the entire Hier-ZSM-5 curve, which represents the concentration of surface acid sites,

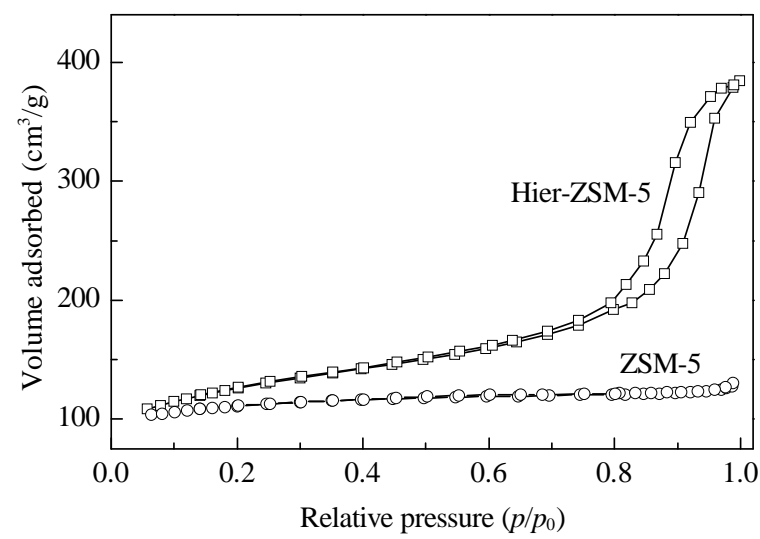

Fig. 3. $\mathrm{N}_{2}$ adsorption-desorption isotherms of ZSM- 5 and hierarchical ZSM-5 zeolites.

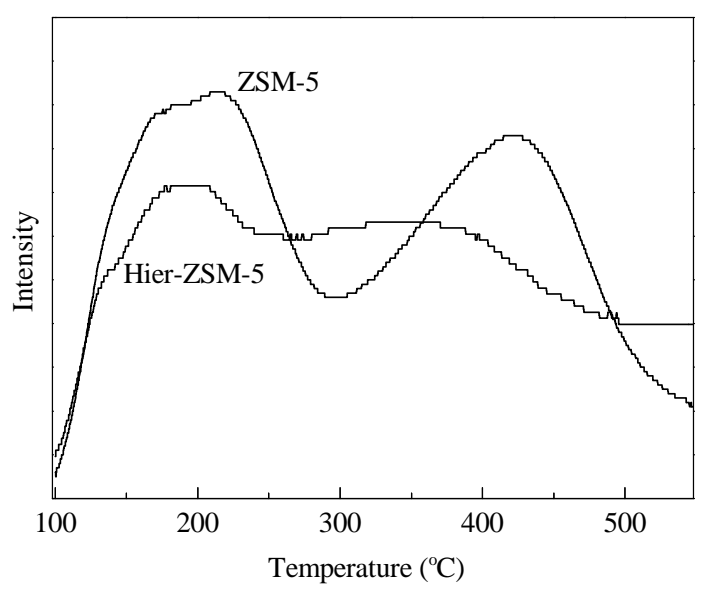

Fig. 4. $\mathrm{NH}_{3}$-TPD profiles of ZSM- 5 and hierarchical ZSM-5 zeolites.

is only $80 \%$ as that of ZSM-5 (Table 1), which is usually ascribed to the low crystallinity. It is worth noting that the above-mentioned $\mathrm{NH}_{3}$-TPD results differ from a report by the same method [13]. One of the possible reasons is that the lack of ion-exchange procedure in the report may lead to insufficient difference in concentration of surface acid sites.

\subsection{Py-IR and DTBPy-IR results}

Py-IR and DTBPy-IR are important tools for characterizing the surface acid sites of solid acidic catalysts, especially zeolites. Usually, when the surface acid sites of zeolites adsorb Py molecules, two characteristic peaks located at approximately 1450 and $1540 \mathrm{~cm}^{-1}$ are visible in the IR spectra and can be ascribed to a Lewis (L) and Brönsted (B) acid, respectively [19-21].

\section{Table 1}

$\mathrm{NH}_{3}$-TPD, Py-IR, and DTBPy-IR data of ZSM-5 and Hier-ZSM-5 zeolites.

\begin{tabular}{lcccccc}
\hline Sample & $\begin{array}{c}\text { Total acid } \\
\text { sites }^{\mathrm{a}}\end{array}$ & $\begin{array}{c}\text { B acid } \\
\text { sites }^{\mathrm{b}}\end{array}$ & $\begin{array}{c}\mathrm{L} \text { acid } \\
\text { sites }^{\mathrm{b}}\end{array}$ & B/L $^{\mathrm{b}}$ & $\begin{array}{c}\text { External } \\
\text { acid sites }^{\mathrm{c}}\end{array}$ & $\begin{array}{c}\text { Si/Al } \\
\text { ratio }^{\mathrm{d}}\end{array}$ \\
\hline ZSM-5 & 6.69 & 9.58 & 1.85 & 7.77 & 0.15 & 96 \\
Hier-ZSM-5 & 5.33 & 3.70 & 3.33 & 1.67 & 1.48 & 103 \\
\hline
\end{tabular}

Calculated from ratio of integrated area of a $\mathrm{NH}_{3}-\mathrm{TPD}, \mathrm{b}$ Py-IR, and cDTBPy-IR; B/L = $1.5 \times$ (B acid sites/L acid sites $)$.

d Determined by ICP-AES. 
Moreover, the Py molecule, which is small enough to enter the ZSM-5 zeolite microporous networks, can be used to detect acid sites both on the external and internal surfaces. Comparatively, the DTBPy molecule size is too large to enter the narrow micropores and therefore, DTBPy-IR only provides an indication of the concentration of external surface acid sites [22].

Figure 5 shows the Py-IR and DTBPy-IR spectra of the ZSM-5 and Hier-ZSM-5 zeolites. It is apparent that Hier-ZSM-5 possesses more $\mathrm{L}$ and less $\mathrm{B}$ acid sites than ZSM-5. The decrease in $\mathrm{B} / \mathrm{L}$ demonstrates that more $\mathrm{Al}$ atoms on the $\mathrm{Si}-\mathrm{O}-\mathrm{Al}$ frameworks were exposed to the external surface in the hierarchical structure, which transferred B acid sites into L acid sites. Moreover, the peak intensity at $1490 \mathrm{~cm}^{-1}$ represents the total concentration of acid sites. In Fig. 5(a), the total acid sites of Hier-ZSM-5 is lower than that of ZSM-5, which is accordance with the $\mathrm{NH}_{3}$-TPD results.

For the DTBPy-IR spectra, Hier-ZSM-5 possesses an apparent peak at $1616 \mathrm{~cm}^{-1}$ with greater intensity than the ZSM-5 zeolite. This indicates as much as an order of magnitude higher concentration of acid sites on the external surface, calculated from the area integral and listed in Table 1.

Therefore, most acid sites are located on the internal surface of the conventional ZSM-5, but the hierarchical structure exposed lots of such acid sites to the external surface, which lead to improved diffusion. Higher catalytic activity in reactions involving bulky molecules should therefore be expected $[13,15,17]$.

\subsection{Catalytic performance}

As an important chemical, $p$-xylene (PX) finds much application in industry. The isomerization of $o$-xylene is one of the important ways for producing PX, and ZSM-5 is known to be a shape selective catalyst to improve the PX content in its isomerization $[23,24]$. The catalytic properties of ZSM-5 and Hier-ZSM-5 zeolites were investigated with results listed in Table 2. The Hier-ZSM-5 demonstrated higher conversions of $o$-xylene but lower PX selectivity than ZSM-5 zeolite at all temperatures tested. In general, however, the yield of PX is influenced by temperature; for example, Hier-ZSM-5 possesses a lower yield at low temperature $\left(T=300{ }^{\circ} \mathrm{C}\right)$, which increased more at high temperature $\left(T=400\right.$ and $\left.500{ }^{\circ} \mathrm{C}\right)$. Considering the complicated influencing factors in catalysis, e.g., surface acid sites, porous structure, and diffusion, a reasonable integrated effect can be explained as follows. The hierarchical structure exposed many acid sites to the external surface, improved diffusion in its porous networks, and thereby, exhibited higher catalytic activity. However, the acid sites on the external surface possess poor shape selectivity, leading to lower selec-
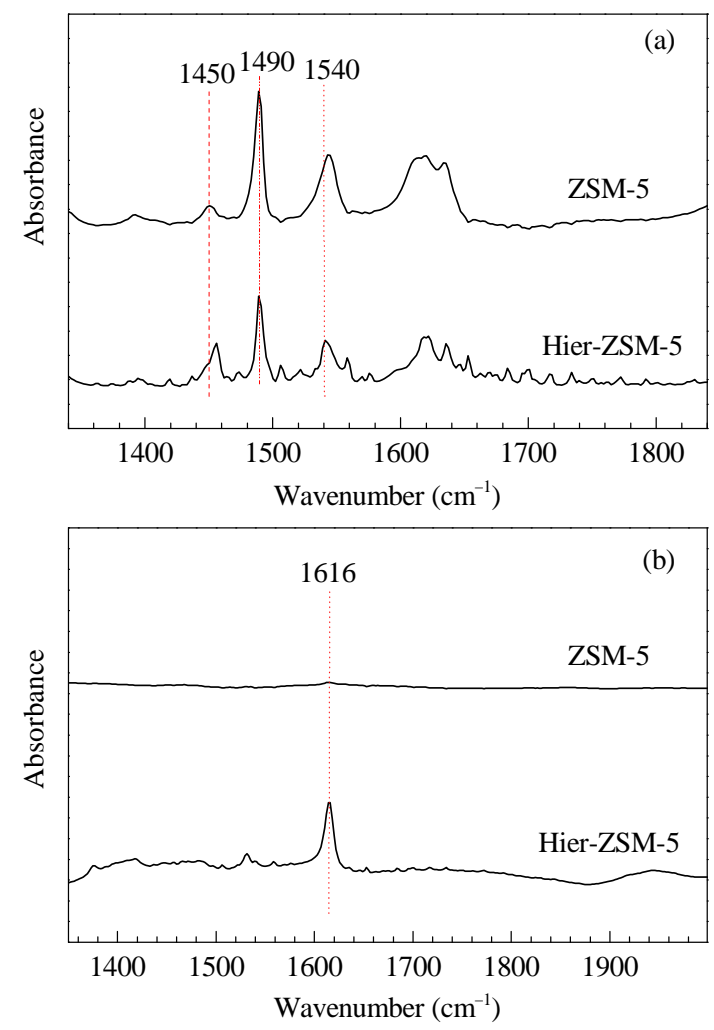

Fig. 5. Py-IR (a) and DTBPy-IR (b) spectra of ZSM-5 and hierarchical ZSM-5 zeolites.

tivity for PX.

\section{Conclusions}

The surface acid sites of hierarchical zeolites play an important role in their catalytic application. To identify the species and distribution of acid sites in hierarchical ZSM-5 zeolite and its effect on diffusion and catalytic properties, characterization of TPD and in-situ IR was performed. The hierarchical structure influenced the inherent crystallinity of ZSM-5 zeolites and exposed abundant aluminum atoms out of the Si-O-Al frameworks, which lead to more Lewis acids located on the external surface. Improved catalytic activity was demonstrated in the isomerization of $o$-xylene. However, the hierarchical ZSM-5 zeolite possesses a decreased selectivity for $p$-xylene in the products for the lower shape selectivity of external acid sites. In conclusion, such characterization methods for surface acid sites are hoped to demonstrate extensive applicability to other hierarchical zeolites, and their application in catalysis may require more attentive examination in future.

Table 2

Conversion of $o$-xylene $(X)$ and selectivity $(S)$ and yield $(Y)$ of $p$-xylene (PX) at different temperatures using ZSM-5 and Hier-ZSM-5 zeolites as catalysts.

\begin{tabular}{|c|c|c|c|c|c|c|c|c|c|}
\hline \multirow{2}{*}{ Sample } & \multicolumn{3}{|c|}{$T=300^{\circ} \mathrm{C}$} & \multicolumn{3}{|c|}{$T=400^{\circ} \mathrm{C}$} & \multicolumn{3}{|c|}{$T=500^{\circ} \mathrm{C}$} \\
\hline & $X / \%$ & $S(\mathrm{PX}) / \%$ & $Y(\mathrm{PX}) / \%$ & $X / \%$ & $S(\mathrm{PX}) / \%$ & $Y(\mathrm{PX}) / \%$ & $X / \%$ & $S(\mathrm{PX}) / \%$ & $Y(\mathrm{PX}) / \%$ \\
\hline ZSM-5 & 18.2 & 32.9 & 6.02 & 27.1 & 29.8 & 8.12 & 35.7 & 25.7 & 9.2 \\
\hline Hier-ZSM-5 & 21.3 & 24.2 & 5.15 & 38.7 & 26.5 & 10.3 & 51.6 & 22.4 & 11.6 \\
\hline
\end{tabular}

Reaction conditions: mass of catalyst $=0.1 \mathrm{~g}$, flow of $o$-xylene $=0.1 \mathrm{ml} / \mathrm{min}$, flow of $\mathrm{N}_{2}=50 \mathrm{ml} / \mathrm{min}$. 


\title{
Graphical Abstract
}

Chin. J. Catal., 2013, 34: 1429-1433 doi: 10.1016/S1872-2067(12)60602-0

Hierarchical mesoporous ZSM-5 zeolite with increased external surface acid sites and high catalytic performance in $o$-xylene isomerization

ZHOU Jian, LIU Zhicheng*, LI Liyuan, WANG Yangdong, GAO Huanxin, YANG Weimin, XIE Zaiku*, TANG Yi

Shanghai Research Institute of Petrochemical Technology, SINOPEC;

Fudan University

Hierarchical mesoporous ZSM-5 zeolite synthesized by the steam-assisted crystallization method exposes lots of acid sites on the external surface, thereby improving catalytic activity in the isomerization of $o$-xylene.

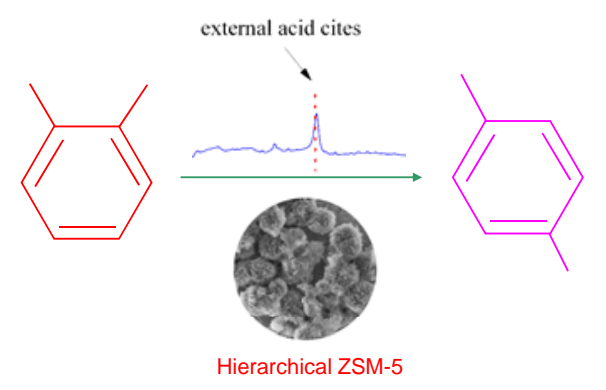

\section{References}

[1] Liu Z C, Wang Y D, Xie Z K. Chin J Catal (刘志成, 王仰东, 谢在库. 催化学报), 2012, 33: 22

[2] Corma A. Chem Rev, 1997, 97: 2373

[3] Cundy C S, Cox P A. Chem Rev, 2003, 103: 663

[4] Tao Y S, Kanoh H, Abrams L, Kaneko K. Chem Rev, 2006, 106: 896

[5] Cejka J, Mintova S. Catal Rev-Sci Eng, 2007, 49: 457

[6] Hua Z L, Zhou J, Shi J L. Chem Commun, 2011, 47: 10536

[7] Liu Y, Zhang W Z, Pinnavaia T J. J Am Chem Soc, 2000, 122: 8791

[8] Jacobsen C J H, Madsen C, Houzvicka J, Schmidt I, Carlsson A. J Am Chem Soc, 2000, 122: 7116

[9] Xiao F S, Wang L F, Yin C Y, Lin K F, Di Y, Li J X, Xu R R, Su D S, Schlogl R, Yokoi T, Tatsumi T. Angew Chem, Int Ed, 2006, 45: 3090

[10] Wang H, Pinnavaia T J. Angew Chem, Int Ed, 2006, 45: 7603

[11] Choi M, Cho H S, Srivastava R, Venkatesan C, Choi D H, Ryoo R. Nat Mater, 2006, 5: 718

[12] Zhou J, Hua Z L, Shi J L, He Q J, Guo L M, Ruan M L. Chem Eur J, 2009, 15: 12949

[13] Zhou J, Hua Z L, Liu Z C, Wu W, Zhu Y, Shi J L. ACS Catal, 2011, 1:
287

[14] Groen J C, Bach T, Ziese U, Paulaime-van Donk A M, de Jong K P, Moulijn J A, Perez-Ramirez J. J Am Chem Soc, 2005, 127: 10792

[15] Christensen C H, Johannsen K, Schmidt I, Christensen C H. J Am Chem Soc, 2003, 125: 13370

[16] Schmidt I, Krogh A, Wienberg K, Carlsson A, Brorson M, Jacobsen C J H. Chem Commun, 2000: 2157

[17] Choi M, Na K, Kim J, Sakamoto Y, Terasaki O, Ryoo R. Nature, 2009, 461: 246

[18] Han Y, Xiao F S. Chin J Catal (韩宇, 肖丰收. 催化学报), 2003, 24: 149

[19] Topsøe N Y, Pedersen K, Derouane E G. J Catal, 1981, 70: 41

[20] Groen J C, Peffer L A A, Moulijn J A, Perez-Ramirez J. Microporous Mesoporous Mater, 2004, 69: 29

[21] Xie Z K, Chen Q L, Zhang C F, Bao J Q, Cao Y H. J Phys Chem B, 2000, 104: 2853

[22] Musilova-Pavlackova Z, Zones S I, Cejka J. Top Catal, 2010, 53: 273

[23] Wang C C, Zheng S A. Chin J Catal (汪长春, 郑绳安. 催化学报), 1992, 13: 448

[24] Kong D J, Liu Z C, Fang D Y. Chin J Catal (孔德金, 刘志成, 房鼎业. 催化学报), 2009, 30: 885

\section{多级孔ZSM-5分子節: 丰富的外表面酸中心和良好的二甲苯异构化催化性能}

\author{
周 健 ${ }^{\mathrm{a}, \mathrm{b}}$, 刘志成 ${ }^{\mathrm{a}}$, 李丽媛 ${ }^{\mathrm{a}}$, 王仰东 ${ }^{\mathrm{a}}$, 高焕新 ${ }^{\mathrm{a}}$, 杨为民 ${ }^{\mathrm{a}}$, 谢在库 ${ }^{\mathrm{a}}$, , 唐 臨 ${ }^{\mathrm{b}}$ \\ a中国石油化工股份有限公司上海石油化工研究院, 上海201208 \\ b复旦大学化学系, 上海200433
}

\begin{abstract}
摘要: 多级孔沸石分子篮的结构性质及其催化性能是近年来分子笁研究的热点. 本文采用蒸汽辅助晶化的方法制备了多级孔 ZSM-5沸石分子笁, 采用 $\mathrm{NH}_{3}$ 程序升温脱附和原位吸附红外光谱等方法研究了其表面酸性质, 用邻二甲苯异构化反应考察了其催 化性能. 结果表明, 多级孔结构分子笁的结晶度和总酸量有所下降, 但Lewis酸中心却有所增加. 进一步研究发现, 多级孔结构分 子篮的外表面酸中心数量远高于常规分子篮, 从而证实了多级孔结构可以将更多的酸中心暴露到外表面; 而外表面酸中心数量 的增多和扩散传质的改善是多级孔ZSM-5分子笁在邻二甲苯异构化反应中具有更高催化活性和对二甲苯产率的重要原因.

关键词: 多级孔结构; ZSM-5分子篮; 表面酸中心; 催化; 二甲苯异构化

收稿日期: 2013-02-24. 接受日期: 2013-04-10. 出版日期: 2013-07-20.

*通讯联系人. 电话: (021)68462197; 传真: (021)68462283; 电子信箱: liuzc.sshy@sinopec.com

\#通讯联系人. 电话: (021)68462197; 传真: (021)68462283; 电子信箱: xzk@sinopec.com

基金来源：国家重点基础研究发展计划(973计划, 2009CB623506); 中国博士后科学基金(2012M510101); 高性能陶瓷和超微结构 国家重点实验室开放课题基金(SKL201208SIC); 上海市博士后科研资助计划(12R21422000).

本文的英文电子版由Elsevier出版社在ScienceDirect上出版(http://www.sciencedirect.com/science/journal/18722067).
\end{abstract}

